\title{
Relationships between ego-oriented peer climate, perceived competence and worry about sport performance: A longitudinal study of student-athletes
}

\author{
Joakim INGRELL ${ }^{1} \bullet \mathrm{Urban}^{\mathrm{JOHNSON}}{ }^{1,2} \bullet$ Andreas IVARSSON ${ }^{2}$
}

$\mathrm{U}$ sing a sample of student-athletes' $(\mathrm{N}=64)$ first year (seventh grade) enrolled at a school with a sport profile, the aim of this longitudinal study was to investigate (a) levels and changes as regards to worry about sport performance, perception of peer climate, and perceived competence; and (b) the relationship in levels and changes between these studied variables. The primary results from latent growth models (LGMs) and parallel process LGMs revealed that, during their first year, the student-athletes' level of worry and perceived ego-oriented peer climate increased, whereas perceived competence decreased. Further, the results showed that perceived competence was negatively associated with worry at the beginning of the students' first year. The slope of perceived ego-oriented peer climate was positively associated with the slope of worry. Future research in relation to the findings is discussed, and recommendations for future actions are given.

Keywords: achievement goal theory, motivational climate, peers, studentathlete, worry

${ }^{1}$ Department of Sport Sciences, Malmö University, Sweden

${ }^{2}$ Center of Research on Welfare, Health and Sport, Halmstad University, Sweden 


\section{Introduction}

Student-athletes selected to attend schools with a sport profile at the age of twelve are often considered to be among the best in their age group in their respective sports. Beside the joy of spending more time doing what they love and hopefully improving their athletic ability - their competence will probably be questioned for the first time, not only by their peers but also by the students themselves in relation to their peers (Nicholls, 1992). Organized sport during leisure time, as well as within a school context, is often considered to play a major part in the development of adaptive or maladaptive behaviors in youth. Two contexts within the organized youth sport domain are training and competition. In these contexts, peer relations have been argued to be an important aspect regarding the quality and duration of sport participation (Smith, 2003). When training and competing, reinforcement from peers could shape athletes' experience of sport. Based on its interpretation, peer reinforcement could be linked to performance anxiety, which also has been argued to affect the quality and duration of sports participation (Smith, Smoll, \& Passer, 2002). In the present study, the focus is on sport performance anxiety and its antecedents. More specifically, we investigate levels and changes in worry, perceived egooriented peer climate, and perceived competence during student-athletes' first year at a school with a sport profile. The perception and interpretation of cognitive and physiological symptoms associated with anxiety are important to recognize because of their direct effects upon performance and competitive behavior. Research has, for example, indicated that children between the ages of 7 and 12 - who experience arousal, which is then interpreted as anxiety - tend to interpret physical symptoms (e.g., sweating or trembling) as signals of danger (Muris, Hoeve, Meesters, \& Mayer, 2004). Within sporting activities where a child's performance is being assessed by social agents (e.g., peers, parents, and coaches), this type of interpretation could cause the child to experience a potentially positive challenge as a threat-leading to task-irrelevant cognitive and emotional responses, anxiety, and, potentially, avoidance (Roberts, Treasure, \& Conroy, 2007).

Anxiety in relation to competition or performance has been identified as an important predictor of the quality and duration of experience in sport, particularly in a youth/junior context (Smith et al., 2002). For instance, Lundqvist, Kenttä, and Raglin (2011) found that junior elite athletes, to a higher degree, reported anxiety-like symptoms as facilitating and enhancing performance compared to sub-elite athletes, who were more likely to report such symptoms as debilitating and hindering performance. Furthermore, somatic trait anxiety has also been shown to prompt sport injuries among junior soccer players (Johnson \& Ivarsson, 2011). High levels of performance anxiety are also associated with 
suboptimal performance and reduced pleasure in participating in sporting activities for both adults and children (Scanlan, Babkes, \& Scanlan, 2005; Smith \& Smoll, 1991), and such anxiety could affect continued sports participation (Scanlan et al., 2005). Based on the above, peers are important social agents who could influence performance anxiety and the quality and duration of sporting experiences during childhood and early adolescence, especially peers with whom athletes practice and compete. Having being selected to attend a school with a sport profile could potentially lead to the student-athletes starting to question themselves in relation to student-athletes in other sports attending the school. In addition, they could start to question themselves in relation to student-athletes within the same sport. In their own team or training group, the student-athletes could potentially be questioned because of jealousy on the part of teammates that have not been selected. Furthermore, it could enhance peers' expectations of those selected to the school.

One aspect of achievement goal theory (Ames, 1992; Nicholls, 1992) is that the situation plays a central role in the motivation process. Research within achievement goal theory has examined how perceived motivational climate affects the likelihood of an individual to become either task or ego involved in an achievement situation. This is then assumed to affect the individual's cognitions, affective responses, and achievement behaviors through their perception of the behaviors necessary to demonstrate competence or avoid demonstrating incompetence (Roberts et al., 2007). In a task-oriented motivational climate (mastery) - where success is based on self-referenced criteria - coaches, peers, and parents encourage effort, improvement, learning, and competence. From a learning perspective, mistakes are seen as a part of development, and feedback is given accordingly. In contrast, an ego-oriented climate (performance) evaluates and enhances success and competence on the basis of a normative standard and follows up with punitive feedback regarding mistakes and negative assessment of athletes' abilities (Ames, 1992; Nicholls, 1992). A perceived ego-oriented motivational climate that emphasizes normative success and penalizes athletes for making mistakes is likely to result in negative affective outcomes such as feelings of anxiety. Current research findings have, to some extent, supported the theoretical link between different motivational climates and negative affects. In an experimental study, Smith, Smoll and Barnett (1995) showed that by teaching coaches to create a more mastery-oriented climate, they could reduce sport performance anxiety in male children, thereby proving that the motivational climate can influence youth athletes' sport performance anxiety levels and that these levels can change during a sporting season. Furthermore, Yoo (2003) reported that novice tennis players in a mastery environment created by coaches experienced less performance anxiety compared to the ego involving climate, where no changes on the anxiety levels were revealed. Moreover, 
Abrahamsen, and Pensgaard (2012) found, in female handball players, that a perceived decrease of a mastery environment created by coaches was related to a decreasing perception of athletic ability, which in turn was associated with more anxiety about performance.

With regards to peer relationship, Smith, Ullrich-French, Walker II, and Hurley (2006) found that youth sport participants (10-14 years) who reported a more adaptive peer relationships profile (i.e., high perception of acceptance, high perception of positive friendship quality, and relatively low perception of friendship conflict) also reported higher perceived competence and lower anxiety. In contrast, Vazou, Ntoumanis, and Duda's (2006) study showed that coachcreated ego climate predicted sport performance anxiety in athletes between the age of 12 and 17, while perceived ego involving peer climate did not. This nonsignificant finding for ego-oriented peer climates was acknowledged as being unsurprising due to coaches having higher authority than peers and, therefore, being more likely to invoke feelings of anxiety in athletes (Vazou et al., 2006).

A basic tenet in achievement goal theory is that motivational and affective reactions caused by the prevalence of one or the other goal state and motivational climate, would be influenced by participants' perceived competence (Roberts et al., 2007). As athletes progress from middle childhood (7-12 years) to adolescence (13-18 years) - particularly those youth athletes selected to attend a school with a sport profile - they experience an increase in the number of sources for feedback available to judge their competence or ability in relation to normative standards (Horn, 2004). Therefore, it is advantageous to simultaneously, and longitudinally, study the relationship between perceived ego-oriented peer climate, perceived athletic competence, and worry about sport performance in a sample of student-athletes attending their first year (seventh grade) at a school with a sport profile.

The aim of this study was two folded: The first aim was to examine trajectories (i.e., levels and changes) of worry, perceived ego-oriented peer climate, and perceived competence in adolescent student-athletes enrolled at a school with a sport profile. Based on the possible increase in the number of sources for feedback (Horn, 2004) - these sources create a normative reference group in which the student-athletes can judge their competence against - and potentially more emphasis on normative success among peers, we hypothesized the following: Firstly, we hypothesized (H1) that worry will increase over an eight-month period (i.e., the students' first year at a school with a sport profile). Secondly, we hypothesized (H2) an increase in perceived ego-oriented peer climate. Thirdly, we hypothesized (H3) a decrease in perceived competence. 
Our second aim was to examine the associations in levels and changes between worry, perceived ego-oriented peer climate, and perceived competence. In line with contemporary theoretical reasoning and previous empirical research, we hypothesized ( $\mathrm{H} 4)$ a negative association between perceived competence and worry over time. Furthermore, we hypothesized (H5) that ego-oriented peer climate will be negatively associated with competence over time. Finally, we hypothesized (H6) that ego-oriented peer climate will be positively associated with worry over time.

\section{Method}

\section{Participants}

Participants were a cohort of Swedish student-athletes $(\mathrm{N}=64,39$ males and 25 females) all born in 2000 and attending their first year in a communitybased school with a sport profile (seventh grade, 12-13 years old). This school has a regional uptake, and the pupils attending are admitted based on interviews and skills in their specific sports. Although the school offers the same educational content as other compulsory schools in Sweden, the major difference is the daily sports training on the students' schedules. Training hours are included in both elective and physical education classes, and the student-athletes in this cohort have one and a half hours of sport-specific training four days a week during school hours. Moreover, these pupils also participated in organized sport during their leisure time. The sports represented by the participants in this cohort were football (soccer), ice hockey, floorball, tennis, swimming, diving, badminton, and figure skating. .

\section{Instruments}

We used Peer Motivational Climate in Youth Sport Questionnaire (PeerMCYSQ) (Ntoumanis \& Vazou, 2005) to measure perceived peer-created motivational climate in the student-athletes' main sport training groups during leisure time. In this study, only the two subscales capturing ego-oriented peer climate was used. The stem for each item was "Most athletes in my training group...," and it contains nine items capturing ego-oriented features: intra-team competition and ability (5 items; e.g., "Encourage each other to outplay their teammates") and intra-team conflict (4 items; e.g., "Make negative comments that put their teammates down"). Response options fall on a 7-point Likerttype scale ranging from 1 (strongly disagree) to 7 (strongly agree). Using all nine perceived ego-oriented questions generated a peer ego mean score $(\alpha>.70$ for all time points). Validity of the PeerMCYSQ has been supported in previous work (Ntoumanis \& Vazou, 2005; Smith, Gustafsson, \& Hassmén, 2010; Vazou, Ntoumanis, \& Duda, 2006). 
We used a modified version of Sport Anxiety Scale-2 (SAS-2, Smith, Smoll, Cumming, \& Grossbard, 2006) to measure the student-athletes' worry. Based on previous research on sport performance anxiety, especially research conducted with the Sport Anxiety Scale (e.g., Smith et al., 1995; Abrahamsen \& Pensgaard, 2012), sport performance anxiety is viewed as a quasi-trait, that is, a somewhat stable trait that can be modified by appropriate situational characteristics. The original questionnaire (SAS-2) consists of three subscales that assess somatic anxiety (five items), worry (five items), and concentration disruption (five items). The validity and reliability of SAS-2 have been supported in previous work (e.g., Smith et al., 2006; Smith, Smoll, \& Cumming, 2007; Grossbard, Smith, Smoll, \& Cumming, 2009) with a total anxiety alpha coefficient of .93. The stem was "Before I compete in my main sport...," and in this study, only the subscale capturing the student-athletes' worry (5 items; e.g., "I worry that I would let others down") was used ( $\alpha>.70$ for all time points). Participants responded to the items on a 4-point Likert-type scale ranging from 1 (not at all) to 4 (very much).

We conducted the Swedish translation of SAS-2 according to standard translation and back-translation procedures (Maneesriwongul \& Dixon, 2004). First, an interpreter translated the English version of the questionnaire into Swedish; thereafter, another independent bilingual interpreter translated the same items back into English. Second, the original English version was compared to the back-translated version, and all errors and discrepancies were identified. The back-translation comparison process was used until all the discrepancies were eliminated. The final version exhibited no contradictions with the original English version of the measures when back translated. To assess the student-athletes' perceptions of their athletic competence, they responded to the statement "I feel competent in my sport" using a Likert-type scale ranging from 1 (not at all) to 5 (very much). This question was a part of our test battery's background questions, also providing information regarding, for example, gender and hours training and competing.

\section{Procedure}

Before conducting the study, we received approval from the Regional Ethical Review Board. We obtained informed consent from all participating student-athletes and their parents before the completion of the questionnaires. We conducted the surveys in a classroom setting with only the first researcher present, who read each item in the questionnaires to the students. They were encouraged to answer honestly and ask questions if they were confused. They were also reassured that there were no right or wrong answers and that their responses would be kept confidential. Data collection 1 was held in August 2013. Data collection 2 was held four months later in December 2013. Four months later, in April 2014, data collection 3 was held. 


\section{Statistical Analysis}

In the present study, focusing on both between as well as within-person change, we used latent growth modeling (LGM; Stenling, Ivarsson \& Lindwall, 2016; Wang \& Wang, 2012). To answer our hypotheses, we first conducted unconditional LGMs for worry, competence, peer task- and ego-oriented climate separately across the three time points, where the intercepts represent the student-athletes' overall level at the beginning of seventh grade (first time of measure) and the slope represents overall change trajectories across the three time points. The variance represents individual differences in intercept and slope factors. The covariance/correlation between intercept and slope factors represents the relationship between scores at the first measurement point and the rate of change. Furthermore, we used parallel-process latent growth modeling (Cheong, MacKinnon, \& Khoo, 2003; Stenling et al., 2016; Wang \& Wang, 2012) to investigate the relationship in change between our variables (i.e., worry, competence, peer ego-oriented climate). Based on the theoretical assumption that the growth of these variables is correlated, we found it advantageous to have these outcomes modeled simultaneously. The covariance/correlation between the latent intercepts would provide information about the association between the two outcomes at the beginning of the observation time period; the covariance/correlation between the latent slopes would indicate how the rates of changes in the two outcomes were associated with each other. Since our data collection started when the student-athletes began their first year (seventh grade) at the school with a sport profile, the intercept was specified at the first time of measure. Data were analyzed using Mplus (version 7.4) with robust maximum likelihood estimator (Muthén \& Muthén, 1998-2015).

The following fit indices were used: chi-square statistics, Bentler's Comparative Fit Index (CFI), and root mean square error of approximation (RMSEA) with $90 \%$ confidence interval (CI). The hypothesized model fits the data well when the $\mathrm{p}$ value associated with the chi-square test is not statistically significant (Wang \& Wang, 2012). Additionally, if the values of CFI are $>.95$ and the values of the RMSEA are <.06, a good fit between the hypothesized model and the observed data exists (Hu \& Bentler, 1999). When conducting the unconditional growth model for worry, a small, not statistically significant, negative residual variance $(\beta=-.004, p=.977)$ was found at the first measurement point (worryT1). This was a problem, due to the fact that variances cannot be negative by definition, probably caused by a small sample size. In line with recommendations (Muthén \& Muthén, 1998-2015), this variable’s residual variance was constrained to zero. 
Ego-oriented peer climate, competence and worry

\section{Results}

The overall fit of the unconditional latent growth models and estimates of the intercept and slope components are presented in Table 1.

\begin{tabular}{|c|c|c|c|}
\hline $\begin{array}{l}\text { Estimates of } \\
\text { parameters }\end{array}$ & Worry & Peer Ego & Competence \\
\hline \multicolumn{4}{|l|}{ Means } \\
\hline $\begin{array}{l}\text { Intercept } \\
(\alpha 1)\end{array}$ & $2.17 * *(.09)$ & $3.67 * *(.12)$ & $4.21 * *(.08)$ \\
\hline Slope $(\alpha 2)$ & $.11 *(.04)$ & $.15^{*}(.07)$ & $-.19 * *(.06)$ \\
\hline \multicolumn{4}{|l|}{ Variances } \\
\hline $\begin{array}{l}\text { Intercept } \\
(\Psi 11)\end{array}$ & $.51 * *(.09)$ & $.65^{* *}(.23)$ & $.23(.13)$ \\
\hline $\begin{array}{l}\text { Slope } \\
(\Psi 22)\end{array}$ & $.10 *(.05)$ & $.14(.07)$ & $.14(.07)$ \\
\hline \multicolumn{4}{|l|}{ Covariances } \\
\hline$\Psi 21$ & $-.11 *(.04)$ & $-.09(.08)$ & $-.02(.08)$ \\
\hline \multicolumn{4}{|l|}{ Correlations } \\
\hline r21 & $-.47 * *(.14)$ & $-.29(.20)$ & $-.12(.37)$ \\
\hline \multicolumn{4}{|l|}{$\begin{array}{l}\text { Fit of } \\
\text { the models }\end{array}$} \\
\hline & $\chi^{2}(\mathrm{df}=2 ; \mathrm{N}=64)=0.381$ & $\chi^{2}(\mathrm{df}=1 ; \mathrm{N}=64)=0.437$ & $\chi^{2}(\mathrm{df}=1 ; \mathrm{N}=64)=0.462$ \\
\hline & $\mathrm{p}=0.8264$ & $\mathrm{p}=0.5084$ & $\mathrm{p}=0.4967$ \\
\hline & $\mathrm{CFI}=1.000$ & $\mathrm{CFI}=1.000$ & $\mathrm{CFI}=1.000$ \\
\hline & $\mathrm{RMSEA}=0.000$ & $\mathrm{RMSEA}=0.000$ & RMSEA $=0.000$ \\
\hline & $\mathrm{CI}=0.000,0.146$ & $\mathrm{CI}=0.000,0.286$ & $\mathrm{CI}=0.000,0.289$ \\
\hline
\end{tabular}

Note. Standard errors are in the parantheses. $\Psi=$ covariance of the Intercept and Slope componenets;

CFI = comparative fit index; RMSEA = root-mean-square error of approximation;

$\mathrm{CI}=90 \%$ confidence intervals for RMSEAs; $* \mathrm{p}<.05 . * * \mathrm{p}<.01$.

Table 1 - Overall Model Fit, Level, and Slope Trajectories for the Unconditional Growth Models $(N=64)$ 
The worry growth model showed good fit, $\chi^{2}(\mathrm{df}=2 ; \mathrm{N}=64)=0.381$; $\mathrm{p}=.8264 ; \mathrm{CFI}=1.000 ; \mathrm{RMSEA}=.000(90 \% \mathrm{CI}=.000-.146)$. On average, there was a significant increase in worry over the three time points $(\alpha 2=.111$, $\mathrm{p}=.011)$. The youth athletes varied significantly regarding worry at the first measurement point (i.e., intercept) $(\Psi 11=.511, \mathrm{p}=.000)$ as well as in regards to slope growth $(\Psi 22=.103, \mathrm{p}=.027)$. This indicates that there was heterogeneity in the sample in regard to how the student-athletes in the sample changed in worry over time.

The growth model as regards to perceived ego-oriented peer climate showed good fit, $\chi^{2}(\mathrm{df}=1 ; \mathrm{N}=64)=0.437 ; \mathrm{p}=.5084 ; \mathrm{CFI}=1.00 ;$ RMSEA $=.000(90 \% \mathrm{CI}=.000-.286)$. On average, there was a statistically significant increase in peer ego over the three time points $(\alpha 2=.149, \mathrm{p}=.022)$. The student-athletes varied significantly regarding peer ego at the first measurement point (i.e., intercept) $(\Psi 11=.654, \mathrm{p}=.004)$ but not in slope growth $(\Psi 22=.136$, $\mathrm{p}=.065)$, indicating homogeneity in the sample in regard to how the studentathletes in the sample changed in peer ego over time.

The competence growth model showed good fit, $\chi^{2}(\mathrm{df}=1 ; \mathrm{N}=64)=$ $0.462 ; \mathrm{p}=.4967$; CFI $=1.000$; RMSEA $=.000(90 \% \mathrm{CI}=.000-.289)$. On average, there was a significant decrease in competence over the three time points $(\alpha 2=-.191, \mathrm{p}=.002)$. The student-athletes did not statistically significant vary regarding worry at the first measurement point (i.e., intercept) $(\Psi 11=$ $.230, \mathrm{p}=.067)$ or in regards to slope growth $(\Psi 22=.137, \mathrm{p}=.060)$, indicating homogeneity in the sample in regard to how the student-athletes in the sample changed in competence over time.

\begin{tabular}{lccc}
\hline Means & Estimate & SE & p value \\
\hline & & & \\
Iworry (intercept) & 2.166 & 0.089 & 0.000 \\
Sworry (slope) & 0.113 & 0.044 & 0.010 \\
Icomp (intercept) & 4.206 & 0.079 & 0.000 \\
Scomp (slope) & -0.193 & 0.062 & 0.002 \\
Iego (intercept) & 3.669 & 0.119 & 0.000 \\
Sego (slope) & 0.154 & 0.066 & 0.019 \\
Variances & & & \\
Iworry (intercept) & 0.512 & 0.089 & 0.000 \\
Sworry (slope) & 0.107 & 0.048 & 0.024 \\
Icomp (intercept) & 0.202 & 0.125 & 0.107 \\
Scomp (slope) & 0.101 & 0.075 & 0.179
\end{tabular}


Ego-oriented peer climate, competence and worry

$\begin{array}{lccc}\text { Iego (intercept) } & 0.695 & 0.236 & 0.003 \\ \text { Sego (slope) } & 0.159 & 0.072 & 0.028 \\ \text { Covariances } & & \\ \text { Iworry <-> Sworry } & -0.109 & 0.044 & 0.012 \\ \text { Iworry <-> Icomp } & -0.156 & 0.073 & 0.032 \\ \text { Scomp <-> Sworry } & -0.038 & 0.030 & 0.204 \\ \text { Icomp <-> Scomp } & 0.002 & 0.080 & 0.977 \\ \text { Iego <-> Iworry } & 0.122 & 0.091 & 0.179 \\ \text { Iego <-> Icomp } & -0.077 & 0.071 & 0.278 \\ \text { Sego <-> Sworry } & 0.063 & 0.025 & 0.011 \\ \text { Sego <-> Scomp } & -0.022 & 0.029 & 0.457 \\ \text { Sego <-> Iego } & -0.112 & 0.086 & 0.189 \\ \text { Correlations } & & & \\ \text { Iworry <-> Sworry } & -0.467 & 0.133 & 0.000 \\ \text { Iworry <-> Icomp } & -0.486 & 0.230 & 0.035 \\ \text { Scomp <-> Sworry } & -0.364 & 0.288 & 0.205 \\ \text { Icomp <-> Scomp } & 0.016 & 0.568 & 0.978 \\ \text { Iego <-> Iworry } & 0.204 & 0.145 & 0.160 \\ \text { Iego <-> Icomp } & -0.205 & 0.180 & 0.255 \\ \text { Sego <-> Sworry } & 0.484 & 0.188 & 0.010 \\ \text { Sego <-> Scomp } & -0.171 & 0.230 & 0.457 \\ \text { Sego <-> Iego } & -0.338 & 0.173 & 0.051\end{array}$

Fit of the model

$$
\begin{gathered}
\chi 2(\mathrm{df}=19 ; \mathrm{N}=64)=10.945 \\
\mathrm{p}=0.9257 \\
\mathrm{CFI}=1.000 \\
\text { RMSEA }=0.000(\mathrm{CI} ; 0.000,0.035)
\end{gathered}
$$

Note. comp = competence; ego = peer ego climate; $\mathrm{CFI}=$ comparative fit index;

RMSEA $=$ root-mean-square error of approximation; $\mathrm{CI}=90 \%$ confidence intervals for RMSEAs.

Table 2 - Latent Growth Curve Evaluating Parallel Process Associations between Worry, Percieved Ego Oriented Peer Climate and Perceived Competence during student-athletes first year (seventh grade) at a sports school $(N=64)$ 
In order to analyze the relationship between ego-oriented peer climate, perceived competence, and worry over time, we conducted a parallel process latent growth model (see Table 2). The parallel process latent growth curve model showed good fit, $\chi 2(\mathrm{df}=19 ; \mathrm{N}=64)=10.945 ; \mathrm{p}=.9257 ; \mathrm{CFI}=1.000$; RMSEA $=.000(90 \% \mathrm{CI}=.000-.035)$. There was a statistically significant and negative correlation between initial status in worry and competence $(r=-.486, p$ $=.035)$, meaning that those reporting higher levels of worry at T1 reported lower levels of competence at T1. With similar association, the slope-slope correlation between competence and worry was negative $(r=-.364, \mathrm{p}=.205)$ but not statistically significant. The correlation between intercepts $(\mathrm{r}=-.205, \mathrm{p}=.255)$, as well as between slopes $(r=-.171, p=.457)$ as regards peer ego and competence was negative but not statistically significant. Although non-significant, these findings indicate a negative relationship between ego-oriented peer-climate and perceived competence. The intercept-intercept correlation between peer ego and worry was positive $(\mathrm{r}=.204, \mathrm{p}=.160)$ but not statistically significant. The slope-slope correlation between peer ego and worry was positive and statistically significant $(\mathrm{r}=.484, \mathrm{p}=.010)$. More specifically, student-athletes with a larger increase in peer ego also had a larger increase in worry.

\section{Discussion}

The purpose of this study was to examine (a) trajectories (i.e., levels and changes) of worry, perceived ego-oriented peer climate, and perceived competence in adolescent-age student-athletes enrolled at a school with a sport profile, and (b) the associations in levels and changes between worry, perceived ego-oriented peer climate, and perceived competence.

In line with our first hypothesis, our findings revealed that the studentathletes' worry increased during the eight-month period. The result also showed that the student-athletes' worry increased independently of their initial levels of worry. Furthermore, there were individual differences in how the studentathletes' worry increased over time. Even though sport performance anxiety have been associated with suboptimal performance and reduced pleasure in participating in sporting activities (Scanlan et al., 2005; Smith \& Smoll, 1991), caution should be used with regards to youth athletes' interpretations of sport performance anxiety levels (Muris et al., 2004; Roberts et al., 2007). We cannot draw any conclusions about how the student-athletes perceived the increase in worry. The student-athletes could potentially perceive their levels of worry as facilitating and enhancing performance. This notion is supported by the findings of Lundqvist et al. (2011). 
Regarding this study's second and third hypotheses, our findings revealed that the perceptions of ego-oriented peer climate increased over the eightmonth period and the perceived competence decreased during the same period, supporting the hypotheses. Interestingly, there was homogeneity in the sample as regards to the slopes of both perceived ego-oriented peer climate and perceived competence. This indicated that the student-athletes had similar growth curves in perceiving the peer climate to be ego-oriented (i.e., increase) and perceiving themselves to be competent (i.e., decrease). A possible explanation for the similar growth curves could be that the student-athletes went through the same transition and experienced an increase in the number of sources of feedback available to evaluate their competence (Horn, 2004). A social normative comparison as such with regards to athletic competence may create a larger uncertainty element (Yoo, 2003), though it is influenced by the perceived skill level other athletes have, and is, therefore, more likely to cause the studied student-athletes to worry about their performance. The decline in perceived competence found in our result could potentially reduce the studentathletes' confidence to successfully demonstrate competence. From a theoretical point of view, an ego-oriented climate could increase the level of uncertainty due to feedback from others (Yoo, 2003; Roberts et al., 2007). Potentially, feedback from others could decrease the student-athletes' control over behaviors necessary to demonstrate competence, thereby create more worries about sport performance.

In relation to our fourth hypothesis (a negative association between perceived competence and worry over time), our findings could only partially confirm the hypothesis. We did not find any statistically significant negative association over time. In regard to our sample, the negative correlations $(r=-.364)$ may still provide us with useful information about the relationship in change between these variables in the sense that these two variables travel together over time. For example, the student-athletes who decrease in competence over time tend to increase in worry during the same period. The statistically significant negative correlation that was found between competence and worry at the intercept in our study (e.g., from a cross-sectional point of view) seems to confirm what Smith et al (2006) found in their study.

In regard to our fifth hypothesis (a negative association between egooriented peer climate and competence among the student-athletes), our findings were in line with the hypothesized associations but not statistically significant. Though not statistically significant, we would like to raise the possibility that the negative relationship could imply that the student-athletes in our sample - who were selected to attend the school - spent more hours doing what they liked (i.e., training during school hours) but perceived themselves to be less competent 
than before. This may sound contradictory. However, we argue that the social normative comparison in an ego-oriented peer climate may cause a decrease in the student-athletes' perceptions of their own competence. An emphasis on normative success leading to athletes questioning their competence would be in line with both empirical findings (e.g., Yoo, 2003) and achievement goal theoretical reasoning (Roberts et al., 2007).

In regard to our sixth hypothesis, our findings reveled statistically significant and positive slope-slope associations between perceived ego-oriented peer climate and worry, whereas the positive intercept-intercept association was not statistically significant, partially supporting the hypothesis. Interestingly, the positive association between ego-oriented peer climate and worry traveled together during the eight-month period (i.e., student-athletes' first year at the school with a sport profile), meaning that those student-athletes that increased in worry also perceived the peer climate to be more ego-oriented. As discussed above, during the student-athletes' first year at the school, they potentially put more emphasis on normative success in relation to their peers, which is likely to cause them to worry more about their performance. The positive association between ego-oriented peer climate and worry is, according to achievement goal theory, conceptually in line with the hypothesized relationships between egooriented climates and affective outcomes. Furthermore, research, for example the study by Vazou et al. (2006), has provided us with empirical support regarding ego-oriented climate, especially that created by coaches, and its relationship with athletes' sport performance anxiety., However, our findings contradict those of Vazou et al. (2006) in that we found support for a positive association between ego-oriented peer climate and worry. This could be explained by the fact that the two studies have different methodological approaches. Vazou et al. (2006) used a cross-sectional approach examining both coach- and peer climates with sport participants with ages ranging from 12-17, whereas our study examined the perceived ego-oriented peer climate following a cohort during their first year (seventh grade, 12-13 years old) at a school with a sport profile. By using longitudinal data with multiple measurements, acknowledging the time aspect together with the fact that most phenomena in psychological research can and will change (e.g., emotions, motivation), we have a solid platform for enhancing our understanding regarding how people change over time (Stenling et al., 2016). This could be contrasted with cross-sectional studies, which only provide a "snapshot" of the outcome and the associated characteristics, at a specific point in time. We believe that we have acknowledged the time aspect by studying an important developmental period during which peer relations play an important role by influencing the quality and duration of sport participation - namely, the transition into adolescence and the first year (i.e., seventh grade) attending a school with a sport profile. 
The small sample size in our study could be a potential limitation since it reduces the possibility to detect substantial differences or effects. Another potential limitation is that our participants consisted of only student-athletes from one school with a sport profile, in contrast to most published research, which focuses on compulsory schools where sport is a part of a broader curriculum. This may limit the degree to which our findings can be generalized to other levels and groups of youth athletes. However, our aim was not to be able to generalize our findings. Rather, we wanted to provide an insight into developmental aspects in high-level student-athletes' sport performance anxiety - more specifically worry, perceived competence, and perception of ego-oriented peer climate during their first year (seventh grade, 12-13 years old) at a school with a sport profile.

\section{Conclusions}

Our study showed that student-athletes increased their level of worry concerning sport performance during their first year at a school with a sport profile. Statistically significant and negative associations were found between student-athletes' perceived competence and worry at baseline. Furthermore, statistically significant and positive associations were found in slope growth between perceived ego-oriented peer climate and worry.

Although the prevalence of affective outcomes in sport to a large extent lies within the climate created by, for example, coaches, parents and peers - athletes' perceived competence is closer to the actual performance. Based on previous research (e.g., Abrahamsen \& Pensgaard, 2012), our findings and the conceptualization of achievement goal theory, we emphasize that research regarding motivational climates' influence on affective outcomes include athletes perceived competence and/or ability. With a larger sample and more observed time points, future research should longitudinally investigate the mediation/ moderation effects between peer-created motivational climate and perceived competence in order to better understand athletes' levels of sport performance anxiety. Furthermore, future longitudinal research should also include whether youth athletes perceive anxiety-like symptoms as facilitating and enhancing performance or as debilitating and hindering performance.

Based on our findings, we suggest awareness over the fluctuation of affective outcomes in sports because these are dynamic. Furthermore, we suggest awareness regarding different transitions in youth sport, and we recommend supporting an environment where youth athletes gain control over their development by focusing more on the task at hand rather than on normative comparison. 


\section{References}

Abrahamsen, F. E., \& Pensgaard, A. M. (2012). Longitudinal Changes in Motivational Climate and Performance Anxiety Among Elite Handball Players. International Journal of Applied Sports Sciences, 24(1), 31-42.

Ames, C. (1992). Achievement goals, motivational climate, and motivational processes. In G. C. Roberts (Ed.), Motivation in sport and exercise (pp. 161-176). Champaign, IL: Human Kinetics.

Cheong, J., MacKinnon, D. P., \& Khoo, S. T. (2003). Investigation of mediational processes using parallel process latent growth curve modeling, Structural Equation Modeling: A Multidisciplinary Journal, 10(2), 238-262. doi:10.1207/ S15328007SEM1002_5

Grossbard, J. R., Smith, R. E., Smoll, F. L., \& Cumming, S. P. (2009). Competitive anxiety in young athletes: Differentiating somatic anxiety, worry, and concentration disruption. Anxiety, Stress, \& Coping, 22(2), 153-166. doi: 10.1080/10615800802020643

Horn, T. S. (2004). Developmental perspectives on self-perceptions in children and adolescents. In M. R. Weiss (Ed.), Developmental sport and exercise psychology: A lifespan perspective (pp. 101-143) Fitness Information Technology Morgantown, WV.

Hu, L., \& Bentler, P. M. (1999). Cutoff criteria for fit indexes in covariance structure analysis: Conventional criteria versus new alternatives. Structural Equation Modeling, 6, 1-55. doi:10.1080/10705519909540118

Johnson, U., \& Ivarsson, A. (2011). Psychological predictors of sport injuries among junior soccer players. Scandinavian Journal of Medicine \& Science in Sports, 21(1), 129-136. doi: 10.1111/j.1600-0838.2009.01057.x

Lundqvist, C., Kenttä, G., \& Raglin, J. S. (2011). Directional anxiety responses in elite and sub-elite young athletes: Intensity of anxiety symptoms matters. Scandinavian Journal of Medicine \& Science in Sports, 21(6), 853-862. doi: 10.1111/j.1600-0838.2010.01102.x

Maneesriwongul, W. and Dixon, J. K. (2004). Instrument translation process: a methods review. Journal of Advanced Nursing, 48(2), 175-186. doi: 10.1111/j.1365-2648.2004.03185.x 
Muris, P., Hoeve, I., Meesters, C., \& Mayer, B. (2004). Children's perception and interpretation of anxiety-related physical symptoms. Journal of Behavior Therapy and Experimental Psychiatry, 35(3), 233-244. doi:10.1016/j.jbtep.2004.03.008

Muthén, L. K., \& Muthén, B. O. (1998-2015). Mplus User's guide (7th ed.). Los Angeles, CA: Muthén \& Muthén.

Nicholls, J. G. (1992). The general and the specific in the development and expression of achievement motivation. In G. C. Roberts (Ed.), Motivation in sport and exercise (pp. 31-56). Champaign, IL: Human Kinetics.

Ntoumanis, N., \& Vazou, S. (2005). Peer motivational climate in youth sport: Measurement development and validation. Journal of Sport and Exercise Psychology, 27(4), 432-455.

Roberts, G. C., Treasure, D. C., \& Conroy, D. E. (2007). Understanding the dynamics of motivation in sport and physical activity: An achievement goal interpretation. In G. Tenenbaum, \& R. E. Eklund (Eds.), Handbook of sport psychology (3rd ed., pp. 1-30). Hoboken, NJ: Wiley Online Library.

Scanlan, T. K., Babkes, M. L., \& Scanlan, L. A. (2005). Participation in sport: A developmental glimpse at emotion. In J. L. Mahoney, R. W. Larson \& J. S. Eccles (Eds.), Organized activities as contexts of development: Extracurricular activities, after-school and community programs (pp. 275-309). Mahwah, NJ: Lawrence Erlbaum.

Smith, A. L. (2003). Peer relationships in physical activity contexts: A road less traveled in youth sport and exercise psychology research. Psychology of Sport and Exercise, 4(1), 25-39.

Smith, A. L., Gustafsson, H., \& Hassmén, P. (2010). Peer motivational climate and burnout perceptions of adolescent athletes. Psychology of Sport and Exercise, 11(6), 453-460. doi:10.1016/j.psychsport.2010.05.007

Smith, R. E., \& Smoll, F. L. (1991). Behavioral research and intervention in youth sports. Behavior Therapy, 22(3), 329-344.

Smith, R. E., Smoll, F. L., \& Barnett, N. P. (1995). Reduction of children's sport performance anxiety through social support and stress-reduction training for coaches. Journal of applied developmental psychology, 16(1), 125-142.

Smith, R. E., Smoll, F. L., \& Cumming, S. P. (2007). Effects of a motivational climate intervention for coaches on young athletes' sport performance anxiety. Journal of Sport \& Exercise Psychology, 29(1), 39-59. 
Smith, R. E., Smoll, F. L., Cumming, S. P., \& Grossbard, J. R. (2006). Measurement of multidimensional sport performance anxiety in children and adults: The sport anxiety scale-2. Journal of Sport and Exercise Psychology, 28(4), 479 .

Smith, R. E., Smoll, F. L., \& Passer, M. W. (2002). Sport performance anxiety in young athletes. . In F. L. Smoll, \& R. E. Smith (Eds.), Children and youth in sport: A biopsychosocial perspective (2nd ed., pp. 501-536). Dubuque, IA: Kendall/ Hunt.

Smith, A. L., Ullrich-French, S., Walker, E., \& Hurley, K. S. (2006). Peer relationship profiles and motivation in youth sport. Journal of Sport and Exercise Psychology, 28(3), 362.

Stenlin, A., Ivarsson, A., \& Lindwall, M. (2016). Cross-lagged structural equation modeling and latent growth modeling. In N. Ntoumanis \& N. D. Myers (Eds.), An introduction to intermediate and advanced statistical analyses for sport and exercise scientists (pp. 131-154). Chichester, West Sussex: John Wiley \& Sons Ltd.

Vazou, S., Ntoumanis, N., \& Duda, J. L. (2006). Predicting young athletes' motivational indices as a function of their perceptions of the coach-and peercreated climate. Psychology of Sport and Exercise, 7(2), 215-233. doi:10.1016/j. psychsport.2005.08.007

Wang, J., \& Wang, X. (2012). Structural Equation Modeling: Applications Using Mplus. Chichester, West Sussex: John Wiley \& Sons Ltd.

Yoo, J. (2003). Motivational climate and perceived competence in anxiety and tennis performance. Perceptual and Motor Skills, 96(2), 403-413. 
Joakim INGRELL is currently a PhD student at the department of sport sciences, at Malmö University, Sweden. His main research interests are: motivation, motivational climate, youth sport and competitive sport.

\section{Corresponding author:}

Joakim Ingrell

Department of Sport Sciences, Malmö University

Nordenskiöldsgatan 10, SE 20506 Malmö, Sweden.

E-mail: joakim.ingrell@mah.se

Urban JOHNSON is a Professor of psychology and sport at the center of research on welfare, health and sport, at Halmstad University, Sweden. He has foremost focused on studying psychosocial risk factors during rehabilitation of long-term injured competitive athletes. Significant keywords in his research are: intervention, prevention, psychosocial risk factors, rehabilitation, coaches and competitive sport.

Andreas IVARSSON is an Associate Professor at the center of research on welfare, health and sport, at Halmstad University, Sweden. His main research interests are psychological aspects related to sport injuries. 